\title{
Teachers' Personal Web Use at Work
}

\section{Dr. Damien Page}

University of Greenwich, Avery Hill Campus, Mansion Site, Bexley Road, Eltham, SE9 2PQ. D.page@ gre.ac.uk

This is an Author's Accepted Manuscript of an article published in Behaviour and Information Technology (2014), copyright Taylor \& Francis, available online at: http://www.tandfonline.com/doi/full/10.1080/0144929X.2014.928744 


\title{
Teachers' Personal Web Use at Work
}

\begin{abstract}
This article presents findings from an online survey of teachers concerning personal web use at work. Often considered as 'cyberslacking' or 'internet abuse', personal web use is a growing phenomenon within increasingly internet-dependent workplaces. The findings of this study highlight a wide range of types of personal web usage amongst teachers ranging from sending personal emails to social networking and personal banking as well as a range of reasons for personal web use from a means of addressing permeable work-life boundaries and coping with work intensification to providing a virtual space for routine resistance. The data also suggest that, rather than being detrimental to the organisation, personal web use could potentially be a means of increasing worker productivity and developing the digital literacy of teachers. It concludes by considering the implications of the findings for senior managers within organisations.
\end{abstract}

Keywords: personal web use at work; cyberslacking; cyberloafing; further education; coping; organisational resistance

\section{Introduction}

It is hard to imagine the contemporary educational workplace without access to the internet. Teachers are expected to create online assessments, populate virtual learning environments with media-rich resources and use online videos via interactive whiteboards. Teaching topics can be researched and created online and the potential of social networking for education has gained ground with Facebook (Yang et al., 2011) and Twitter (Mahoney, 2012) used to engage their highly technologically literate students. Yet the internet can also be problematic in the workplace (Davis, Flett and Besser, 2002) with employees surfing the net, online shopping, uploading holiday pictures to their online profile, forwarding joke emails, all on 'company time' (Case and Young, 2002; Lim et al, 2002). Often conceived of as 'cyberloafing' or 'internet abuse', personal web use (PWU) at work has become the site of academic research since the late 1990s yet has achieved relatively little stability as a conceptual field. For some researchers PWU is problematic, a challenge to network security, and damaging to worker productivity (Weatherbee, 2010); others see it is as a means of managing the permeable barriers between work and home and a method of coping (Eddy, et al., 2010); more recently, a minority of researchers have argued that PWU is a means of increasing productivity by providing short breaks during the work day (Coker, 2011).

The majority of studies have so far focused on the private sector and form the basis of the theoretical framework discussed below; few have focused on educational settings. Given the increasing integration of Information and Communications Technology (ICT) into the work of teachers, this study aimed to investigate the extent of PWU that has accompanied this movement and to explore the potential impact of PWU in the educational workplace. This article will first present an overview of the extant literature and use this as a basis for the discussion of PWU in an educational context. Using (appropriately) an online survey of teachers on an in-service training course, this study examined the frequency and types of PWU on both work PCs and mobile phones as well as the justifications of the participants for their online activities. The analysis revealed the impact of demographic factors such as age and gender but also other considerations such as employment status and whether teachers had their own dedicated PC or shared one. The article concludes that, as well as potentially offering a means of coping and a new means of routine resistance in the workplace, PWU may also increase teachers' productivity and digital literacy. 


\section{Theoretical Framework}

As a relatively new field of research, personal web use at work has yet to become conceptually stable with several competing perspectives developing simultaneously (Kim and Byrne, 2011). However, two broad strands may be identified that define the concept of personal web use (PWU) at work according to its impact upon the organisations within which it takes place and the antecedents of the behaviours. The first strand is the more developed and sees PWU largely as deviant behaviour that is potentially damaging to organisations in terms of lost productivity, reduced bandwidth and network security (Case and Young, 2002). Heavily influenced by workplace deviance models (Robinson and Bennett, 1995; Weatherbee, 2010) and organisational misbehaviour frameworks (Ackroyd and Thompson, 1999; Vardi and Weitz, 2004), here is the territory of 'cyberslacking', 'cyberloafing' and 'internet abuse'. In one of the earlier studies, Lim et al. (2002, p67) defined cyberloafing as

any voluntary act of employees using their companies' Internet access during office hours to surf non work-related Web sites for nonwork purposes, and access (including receiving and sending) nonwork-related email.

Their study highlighted a variety of types of PWU including sending non-work- related emails, general news sites, online shopping and even accessing sites of a pornographic nature in a minority of cases.

Given the wide range of cyberloafing activities, two typologies have been articulated to refine the categorisation: Henle and Blanchard (2008) differentiate between minor cyberloafing that includes sending personal emails and visiting entertainment sites and serious cyberloafing that encapsulates online gambling and pornography. Blau et al. (2006) suggest a three part typology of cyberloafing: 'browsing related', non-work related emails and interactive cyberloafing such as online games or contributing to online discussion forums. However, while there is general agreement about the type of internet activities that constitute cyberloafing (or cyberslacking), there is divergence about the type of employee who is most likely to engage in PWU. Blau et al. (2006) and Ugrin et al. (2007) suggest workers who felt powerless were most likely to cyberloaf while Garrett and Danziger (2008) found that higher status workers were those most likely to loaf online. Several studies have found that gender is the most important determinant, with cyberloafing more prevalent among males (Lim and Chen, 2009, Vitak, et al., 2011; Restubog et al., 2011). Ugrin et al. (2007) argued that gender was not a factor but age was, with young workers more likely to engage in PWU; conversely, Restubog et al. (2011) found that older workers were more likely to cyberloaf.

There is even less consensus in the field when it concerns the causes of cyberloafing/slacking. Eddy et al. (2010) suggest that cyberloafing is one of a suite of 'personal activities on company time' that includes personal phone calls, chatting with colleagues and 'water-cooler' time. Within this paradigm, the primary cause of cyberloafing is the increasing blurring of home and work that is exacerbated by new technologies and the contemporary 'holistic approach to human resource management [that] aims for increased existential exposure of employees so that more of themselves is present at work' (Fleming, 2005, p. 289). From this perspective, rather than seeing cyberloafing as aimless or purely leisure, PWU at work is an attempt to manage the work-life balance by using the internet at work for personal-life tasks such as internet banking. As such, PWU is sometimes presented in terms of time (re)appropriation (Paulson, 2011), a form of workplace resistance. Lim and Teo (2005) also suggest the importance of time re-appropriation as an antecedent of 
cyberloafing and argue that working excessive hours and working at home provide an impetus for employees to engage in PWU at work. Workplace resistance also frames those antecedents that are related to organisational justice (see Zoghbi-Manrique de Lara, 2007) with Liberman et al. (2011) arguing that employees who hold unfavourable job attitudes engage in PWU as a way of restoring control over their work and imbuing their labour with meaning when it was perceived as meaningless. In the work by Lim and Teo (2005) and Stratton (2010), similar patterns of cyber-resistance are discernible with PWU seen as a response to mistreatment and escape from the workplace.

Cyberloafing is not, however, consistently framed as a means of resistance or a reaction to poor organisational justice; in many cases, the causes are far more routine: cyberloafing out of boredom (Skowronski, 2012; Kidwell, 2010); cyberloafing as an accepted group norm in the workplace (Blanchard and Henle, 2008; Pee et al., 2008); the easy accessibility of the internet and its regular use for work purposes (Vitak et al., 2011). Furthermore, the majority of studies found that those who engaged in cyberloafing did not feel bad about it. While some cyberloafers felt guilt (Lim et al, 2002; Stratton, 2010), most felt that it did little harm to their employing organisation (Lim and Teo, 2005) or even that the harm it did was mitigated by the benefits of cohesion between colleagues who were consistently engaged in PWU (Lee et al., 2007), the 'Robin Hood syndrome' of cyberloafing in Lee et al.'s terms.

However, while many studies consider PWU at work as deviant workplace behaviour that is damaging to productivity, other studies, many more recent, suggest that it may actually be of benefit to employees and organisations. Drawing on Deci and Ryan's (2004) selfdetermination theory of motivation, Coker (2011) argues that PWU (or 'workplace internet leisure browsing' in Coker's term) allows employees to experience a greater sense of autonomy in the workplace, thus enhancing their motivation and job satisfaction. Additionally, PWU at work 'provides a way for employees to have a short unobtrusive break which enables concentration to restore' (p240). Coker's study concluded that employees who engaged in PWU at work were more productive than those who did not. However, productivity gains only resulted from short PWU breaks rather than sustained leisure browsing - when PWU consumed more than $12 \%$ of work time, productivity decreased. By providing short breaks, PWU at work functions not just as a means of enhancing productivity but acts also as a method of emotion-focused coping (Henle and Blanchard, 2008; Ugrin et al., 2007). Furthermore, increased productivity is not the only potential benefit of PWU. Seymour and Nadasen (2007) found that PWU led to increased access to perceptions of information literacy while Anandarajan and Simmers (2003) suggest gains in time management skills and balancing home and work life. PWU has even been linked to organisational learning, a position proposed by Belanger and Van Slyke (2002) and Oravec (2002).

Whether positioned as deviance or coping, resistance or proactivity, the vast majority of studies of PWU at work have focused on the private sector as sites of research; few have focused on teachers. McBride et al. (2006) conducted an analysis of the times of courserelated online engagement by school teachers who were also studying at university in the US. Measuring the times of activity on web-based assignments, the authors found that $51 \%$ of online assignment activity by their students was within school hours, times, the authors argue, when their students should have been teaching or preparing lessons. While McBride et al. categorise such behaviour as cyberslacking, they fail to consider such behaviours as potentially beneficial - the participants of their study were using the internet to submit assignments. Achieving additional qualifications as a teacher is, after all, essential as part of 
continuing personal and professional development. Their conclusion is that tighter controls on teachers' use of the internet should be enforced within schools. In a study of PWU in a university, Zoghbi-Manrique-de-Lara (2011) similarly considers it within the organisational deviance paradigm. It was found that there was some connection between cyberloafing and more generalised organisational deviance and that both were found to potentially (although not definitively) affect student satisfaction.

This research proceeds from the perspective of Kim and Byrne (2011) who suggest the term 'personal web use' as an umbrella concept that encapsulates the variety of conceptions of leisure browsing at work. As an exploratory study, it draws on the whole range of perspectives of PWU, deviant and productive, resistance and coping, problematic and mundane. It also attempts to identify the frequency and types of PWU as well as begin to explore its antecedents and the justifications of those who engage in it.

\section{Method}

\subsection{Participants}

The participants in this study were in-service teacher training students who were all employed in the lifelong learning sector which included Further Education (FE) colleges (tertiary vocational institutions), as well as other contexts for training such as the armed forces, the NHS and prison education. All participants were participating in a distance learning programme of teacher training and so were distributed throughout England.

\subsection{Materials and Design}

Data were collected using SurveyMonkey, an online software package that facilitates questionnaire creation. . The survey was designed in four sections: firstly, given the findings of the extant literature concerning sex and age, there were questions regarding demographic information. This section also included employment status and type of provider, length of service, the extent of use of a home PC for work and whether the participants had their own dedicated PC at work or whether they shared one. The second section concerned PWU at work and included questions on the types and frequency of PWU, how common it was in their office and questions regarding the IT policy of their employer. This section also included a question that asked participants to indicate on a Likert scale the extent to which they agreed or disagreed with a list of reasons for engaging in PWU. This question drew on the literature to include antecedents such as stress-relief, organisational justice (how fairly teachers were treated), work-life balance and the notion of PWU not harming the organisation in terms of lost productivity or network security. The final section investigated the extent of PWU that was conducted on web-enabled mobile phones, a phenomenon that has not been included in the extant literature concerning PWU at work.

\subsection{Procedure}

A link to the survey was emailed to 320 participants using their personal email addresses. After the initial invitation to participate, a reminder email was sent five weeks later; the survey was closed three weeks after this. Once the survey had been closed, the data were analysed within SurveyMonkey itself which facilitates statistical analysis and permits crosstabulation between questions. This allowed the researcher to identify patterns of responses based upon individual characteristics of the respondents. The results were analysed according to each demographic factor separately to identify which appeared to most impact upon PWU. In total 110 participants responded, a similar number to PWU studies in noneducation fields (e.g. Liberman et al., 2011). The response rate was 34\%, 3\% above the 
average response rate for email surveys reported by Sheehan (2001); 69.2\% were female and the age range is represented in table 1 below.

\begin{tabular}{|l|c|c|c|}
\hline \multicolumn{4}{|c|}{ Table 1: Gender of Participants } \\
\hline Age & Male & Female & $\begin{array}{c}\text { Response } \\
\text { Percent }\end{array}$ \\
\hline $20-29$ & 3 & 14 & $16.0 \%$ \\
\hline $30-39$ & 9 & 22 & $29.2 \%$ \\
\hline $40-49$ & 16 & 25 & $39.6 \%$ \\
\hline $50-59$ & 4 & 10 & $14.2 \%$ \\
\hline $60-69$ & 0 & 1 & $1 \%$ \\
\hline $70+$ & 0 & 0 & $0.0 \%$ \\
\hline
\end{tabular}

In terms of employment status, $52.3 \%$ were employed full time with $22.5 \%$ permanent fractional and $25.2 \%$ employed on a temporary basis. The majority of respondents $(58.9 \%)$ worked in Further Education colleges with the remainder spread across a variety of other training providers: $12.6 \%$ in sixth forms, $8.4 \%$ in private training providers, $7.4 \%$ in the armed forces and the remainder in prisons, the NHS, the police service, charities, special education organisations and pupil referral units. The length of service varied from $10.2 \%$ who had been employed six months or less and $17.6 \%$ who had been employed for six years or more. Just over half of the respondents $(51.4 \%)$ had their own dedicated PC at work while the remainder shared access and $73.1 \%$ had a mobile phone that could access the internet. Only one participant did not have internet access at home. To investigate the extent of permeable work/home boundaries (see Eddy et al., 2010), participants were also asked how often they used their home PC for work.

\section{Findings}

\subsection{PWU on Computers}

At the beginning of the survey, the term 'personal web use at work' was described and examples were given. $73.8 \%$ of participants engaged in PWU at work to at least some extent. Of those who did engage, the majority (36.9\%) kept it to 30 minutes or less per week. $11.6 \%$, however, used the internet for personal purposes for five or more hours per week; one respondent suggested use of 10 or more hours a week. 23.6\% said they had never read their organisation's policy on web use with $47.2 \%$ having read it in the last year. $53.8 \%$ stated that their PWU use never contravened the policy with $31.1 \%$ stating that it occasionally did; $11.3 \%$ were unsure.

To investigate the types of PWU at work, participants were given a list of 16 of the most common forms of non-work web uses drawn from the literature but also with the inclusion of more contemporary varieties such as micro-blogging (e.g. Twitter). Examples of each type were given. The results are presented in table 2 below. 


\begin{tabular}{|l|c|c|c|c|c|}
\hline \multicolumn{7}{|c|}{ Table 2: Types of PWU } \\
\hline $\begin{array}{l}\text { Use the scale below to state how often you use each of the types of online activities for personal use at } \\
\text { work on your work PC, not as part of your job. Figures in \% }\end{array}$ \\
\hline \multicolumn{1}{|c|}{ Type of PWU } & Never & Occasionally & Often & Extensively & $\begin{array}{c}\text { Very } \\
\text { extensively }\end{array}$ \\
\hline Sending personal emails & 24.5 & 50.9 & 17.0 & 3.8 & 3.8 \\
\hline General web-surfing & 26.7 & 43.8 & 18.1 & 6.7 & 4.7 \\
\hline Reading news & 27.6 & 39 & 23.8 & 6.7 & 2.9 \\
\hline Watching videos (e.g. YouTube) & 44.3 & 37.7 & 13.2 & 4.8 & 0 \\
\hline Searching for jobs & 56.6 & 31.2 & 8.5 & 2.8 & 0.9 \\
\hline Shopping (e.g. Amazon, Tesco) & 57.1 & 31.4 & 8.6 & 2.9 & 0 \\
\hline $\begin{array}{l}\text { Researching and or/booking } \\
\text { holidays }\end{array}$ & 57.5 & 30.3 & 7.5 & 2.8 & 1.9 \\
\hline Personal banking & 58.1 & 27.6 & 10.5 & 3.8 & 0 \\
\hline $\begin{array}{l}\text { Social networking (Facebook } \\
\text { etc) }\end{array}$ & 64.8 & 21 & 10.6 & 1.9 & 1.9 \\
\hline Online auction sites (e.g. eBay) & 74.5 & 18.9 & 4.7 & 1.9 & 0 \\
\hline Send e-cards, flowers or gifts & 76.7 & 19.5 & 1.9 & 1.9 & 0 \\
\hline Buying insurance & 77.4 & 15.1 & 3.8 & 2.8 & 0.9 \\
\hline Downloading music or films & 85.7 & 12.5 & 1 & 1 & 0 \\
\hline $\begin{array}{l}\text { Updating personal blogs or } \\
\text { websites }\end{array}$ & 87.6 & 7.7 & 2.9 & 1 & 1 \\
\hline Microblogs (e.g. Twitter) & 91.4 & 3.8 & 3.8 & 1 & 0 \\
\hline Online games & 94.4 & 3.8 & 0 & 1 & 1 \\
\hline Chat rooms & 96.2 & 3.8 & 0 & 0 & 0 \\
\hline
\end{tabular}

As is clear from table 2, the three most common forms of PWU were sending personal emails, 'general web-surfing', the 'voluntary, aimless, and undirected way of using web access and engaging in non-work-related activities' (Kim and Byrne, 2011) and 'reading news'. What is also clear from the data is that, in general, 'functional' PWU was more common than entertainment or social PWU: searching for jobs, shopping, booking holidays and banking were all found to be more common than social networking via Facebook; the use of Twitter was even less common with $91.4 \%$ of respondents never using it. This finding highlights the permeable nature of the work/home boundary in the education sector - given the fact that $96.3 \%$ of the sample worked at home in addition to their hours at work (just over $40 \%$ extensively or very extensively), it is perhaps unsurprising that tasks associated with personal lives were conducted within the workplace. From a critical perspective, such actions can be seen as a means of time re-appropriation (Ackroyd and Thompson, 1999; Paulson, 2011) whereby workers will reclaim unpaid overtime during regular work hours. While activities such as online banking or shopping may be seen as 'domestic' tasks, PWU involving the search for jobs and holidays may seen as a form of 'cognitive escape' (Page, 2011a), a form of 'routine resistance' (Scott, 1985; Prasad and Prasad, 1998) within 
organisations. From this perspective, while PWU is often seen as aimless organisational misbehaviour, there is a significant resistant element that should not be underestimated from these findings at least, cyber-resistance may be equally as likely as cyber-loafing. However, an alternative interpretation could position many of the forms of PWU within a coping paradigm: the high proportion of personal emails may be seen as a focus on private relationships, a coping strategy within Frydenberg and Lewis' (2002); the high proportion of functional tasks such as banking and shopping may be an attempt to cope with a poor worklife balance.

Cross tabulation of the data on the extent of PWU and the types of engagement provides some significant findings. Only $9.4 \%$ of men stated that they never engaged in PWU at work while for women this figure rises to $34.3 \%$. Of those who do engage, twice as many men as women (18.7\% to $9 \%$ ) spend five or more hours on PWU a week with men using all varieties of PWU more than women except for social networking. Men were also $10 \%$ more likely to think that their PWU contravened their employer's policy. These findings are despite the fact that women are more likely than men to have their own dedicated PC at work $(52.9 \%$ to 46.9\%). Age was also found to be a significant factor with those aged 20-30 spending most time on PWU and most likely to have their own dedicated PC (64.7\%). They were also more likely to contravene organisational policies on web use. Age also appeared to be correlated to the types of PWU with younger participants using online banking and watching online videos far more than older respondents. In terms of employment status, those who were employed on full time permanent contracts were more likely to engage in PWU but were also more likely to search for jobs $(51.9 \%)$ and holidays $(61.1 \%)$ than part time and temporary staff $(25.9 \%$ and $22.2 \%$ respectively). PWU was also influenced by length of service with those employed longer more likely to engage - those employed for six months or less were least likely. The final factor was whether respondents' work PC was shared: those who had their own PC were more likely to engage in PWU. A further crosstabulation concerned the $26.2 \%$ of respondents who stated that they never engaged in PWU. Of these, $88.5 \%$ were female and $53.8 \%$ were aged 40-50 compared to $7.7 \%$ aged $20-30$.

\subsection{Mobile PWU}

PWU at work was not only conducted via office PCs; mobile PWU was also evident. 73.1\% of the sample owned a mobile phone that could access the internet although younger respondents were more likely to own one. $25.6 \%$ said that they preferred to engage in PWU at work on their mobile, $6.7 \%$ said the same amount on both. Of those who preferred to use a mobile for PWU, 81\% were female and $59.1 \%$ were under 40. Just under half were temporary. There was a variety of reasons for mobile PWU given but the most common reason was ethical - many respondents did not agree with using their employers' resources for PWU:

'Because it [phone] is mine not the colleges'.

'It is a personal phone and I pay the bill, therefore I am not abusing work resources'. 'Because I don't agree with using the college PC for personal reasons'.

However, it must be noted that the ethical dimension extended only to the medium used to engage in PWU at work, not the act itself.

For others, mobile PWU was for technical purposes:

'It's easier to access emails and messages'. 
'Quicker access'.

'Because I feel it is safer than the work PC which does not always have the most up to date anti-virus'.

Still others suggested that mobile PWU was about privacy - virtual concealment in Hope's (2007) terms - and, therefore, evading employer security protocols:

'There are some websites I do not feel appropriate or safe to open from the work PC'.

'As its personal'.

'It is not college property'.

Respondents were then asked if there were any sites they would use their mobile to access rather than their work PC. The responses were dominated by social networking with the majority citing Facebook and Twitter. Mobiles were also used to access sites blocked by the organisation such as personal email providers, personal banking, eBay and even online gambling sites. In this regard, mobile PWU at work can be seen as a means of 'making out' (Burawoy, 1979; Noon and Blyton, 1997), a virtual means of getting round official practices and policies. Here, then, the resistant element of PWU at work is again evident.

\subsection{Justification for PWU}

As an exploratory study of PWU, the question concerning justification was informed by the literature. The primary antecedents for PWU identified in the literature were presented as statements and participants were asked to respond on a five point Likert scale: strongly disagree, disagree, neither agree or disagree, agree and strongly disagree. Blau et al. (2006) and Lim and Teo (2005) both argue that organisational justice was a key factor in predicting PWU at work with employees more likely to leisure surf when they held perceptions of being treated unfairly. However, consistent with Restubog et al. (2011), organisational justice was not found to be strongly related to PWU amongst teachers with $81 \%$ of respondents disagreeing or strongly disagreeing that they felt justified over PWU because they were not treated properly. Similarly, PWU at work was not found to be associated with inadequate rewards: $74.5 \%$ disagreed with the justification. The proposition that boredom is a major cause of PWU (Kidwell, 2010; Skowronski, 2012) was also not supported with just 12.9\% suggesting this as a factor. The normalisation of PWU in work environments (Blanchard and Henle, 2008; Liberman et al., 2011) was also weakly correlated with only $15.7 \%$ agreeing or strongly agreeing that they engaged in PWU because everybody else did. More strongly correlated was the connection between working at home and PWU with a third of respondents citing this as a cause and a similar number justifying PWU as doing no harm to the organisation (Selwyn, 2008; Lee at al., 2007).

As well as asking respondents to rate the extent to which they agreed with the statements, the survey also asked if there were any other reasons for engaging in PWU in free text responses. A range of reasons were given:

'A need to access the web during working hours'.

'Sometimes I have a lot of free time on my hands and I don't want to do any work'.

'To ensure I keep on top of my business communications and act promptly when an enquiry or contact approaches me'.

'Convenience - I sometimes forget tasks when I get home so use facilities that are available'. 
'I use Facebook to message my partner as it is more professional than talking on the phone in front of colleagues'.

'To check if I have urgent emails from friends and family'.

'The need to feel up to date. That is the reason why I read news from time to time'.

However, the two most common justifications for PWU in this study are located within the paradigm of PWU that views the behaviour as potentially beneficial to the organisation (Coker, 2011; Belanger and Van Slyke, 2002; Oravec, 2002). As discussed in the theoretical framework, a minority of authors have suggested that PWU at work is not necessarily detrimental to the organisation. Henle and Blanchard (2008) characterise PWU (they use the term cyberloafing) as emotion focused coping of the escape-avoidance type, analogous to disengagement in Carver and Scheier's (1989) scale of coping strategies. Here, PWU is a response to workplace stressors and, given the demands of work intensification (Mather, Worrall and Seifert, 2009) and high levels of stress in the education sector (Court and Kinman, 2008), it is perhaps unsurprising that coping becomes a key attribute for teachers: $42.2 \%$ of respondents to this survey agreed or strongly agreed that PWU at work was a form of stress relief. However, coping as defined by Lazarus and Folkman (1984), is a transaction between the individual and the environment that is seen 'independently from its outcome' (Folkman et al., 1986, p848). Coping, therefore, should be seen as an attempt to manage stressors regardless of its impact. PWU as a coping strategy can therefore be either detrimental or beneficial to the organisation. However, the other primary justification for PWU in this study is beneficial: $43 \%$ of respondents suggested that PWU made them more productive by providing short breaks, an assertion proposed by Coker (2011) and Garrett and Danziger (2008). Here, rather than an act to manage specific stressors within the workplace which characterises escape-avoidance coping, engaging in PWU as a means of increasing productivity can perhaps be seen more proactively and therefore as beneficial to the organisation. The issues of self-reporting must be remembered however; social desirability bias may be a factor in increased productivity being reported as the most common reason for PWU.

Crosstabulation analysis was also conducted on the justifications for web use and again produced some significant findings. First, while gender was found to be a factor in the amount of PWU, it was not found to be a factor in the justifications for PWU with little statistical difference between males and females in the extent to which they agreed with the justifications. However, females were more likely to strongly disagree with the statements concerning boredom and organisational justice. Employment status was also found not to be a predictive factor in the justifications of PWU with percentages similar for all statuses with one exception - full time staff were more likely to agree or strongly agree that PWU was a form of stress relief (52\% of full time staff); $25 \%$ of permanent part time and $37.5 \%$ of temporary staff agreed or strongly agreed.

Length of service and whether participants had their own dedicated PC were similarly found not to be significant factors. Age seemed to be a more significant determinant of the justification for PWU in certain cases: those aged 30-40 were $20 \%$ more likely to view PWU as a form of stress relief than the other age ranges; those aged 20-30 and 30-40 were more likely to see PWU as doing no harm to the organisation; $29.4 \%$ of 20-30s agreed or strongly agreed that PWU was a way to relieve the boredom of their work compared to $10.7 \%$ of those $30-40$ and $7.7 \%$ of $40-50$ s and none above 50 . The younger age groups were also more likely to engage if PWU at work was a group norm. 


\section{Discussion}

The extant literature on PWU at work considers the behaviour in relation to the productivity of employees and the benefit or detriment to the organisation that may result. In an educational context, while PWU could potentially impact upon the organisation, more important is the impact upon students. Where PWU is problematic, cyberloafing may be engaged in instead of preparing high quality lessons; Facebook may be prioritised before marking; watching videos on YouTube may occupy the time when teachers should be creating differentiated resources. It is this concern, together with concerns about network stability and security that drives organisational ICT policies. In this study, the findings suggest that PWU at work can potentially be seen from four perspectives: firstly that PWU as cyber-loafing can be anti-productive and detrimental to the work of teachers; secondly, PWU can be seen as a means of organisational routine resistance against work intensification; thirdly, it can potentially be seen as beneficial for the organisation in terms of providing a means of coping with stress; finally, most tentatively it may even act as a means of continuing professional development in terms of digital literacies. This section will explore each of these perspectives that highlight the conflict between PWU as coping PWU as a means of improving teaching practice.

The first perspective to be considered is that of PWU as deviant, counterproductive workplace behaviour (Weatherbee, 2010; Restubog et al, 2011; Selwyn, 2008). In the private sector, the site of the majority of studies, PWU is seen as damaging to production; in education, when 'production' may be equated with students' learning, the impact is potentially more serious. While it is not clear whether PWU affected teaching and learning or administrative tasks, with $11.6 \%$ of the respondents suggesting that they engaged in PWU at work for five hours or more each week, the impact is likely to be significant. The types of PWU reported in this study are not at the more serious end of the cyberloafing spectrum (Blau et al., 2006) - it is the amount of time taken from the teaching role that is significant. But it is not just the impact upon productivity that is of potential concern; PWU can also have a negative impact upon network bandwidth and network security (Case and Young, 2002). The potential for harm here is more likely when PWU involves high-data activities such as watching videos on YouTube, viewing friends' online pictures and opening attachments in personal emails that may contain viruses. Of further concern is the potential deviance facilitated by social networking. There have been several recent cases of teachers discussing their students in derogatory terms (Reynolds, 2012) or posting updates about their drinking and partying habits (BBC News, 2012). Indeed, in his analysis of disciplinary orders issued by the General Teaching Council for England, the now abolished professional body for school teachers, Page (2012) found misuse of technology to be the fourth most common form of teacher misbehaviour. Such deviant use of the internet is potentially highly damaging to organisations.

There is also a complicating factor concerning PWU as problematic that arises from the methodology of this study: the data discussed here relies on the self-reporting of the participants who, given the deviant associations of PWU at work, may have under-reported the length of time that they spend online, a common feature of surveys (Razavi, 2001). This is particularly relevant to studies that focus on behaviours that may be considered 'deviant' that are subject to 'social desirability bias', the 'pervasive tendency of individuals to present themselves in the most favourable manner relative to prevailing social norms and mores' (King and Bruner, 2000). Alternatively, PWU at work may be so ingrained into daily work routines that participants underestimate the amount of time they spend on PWU, especially 
when the internet is used regularly for work purposes (Vitak, et al., 2011). It is possible that the levels of PWU at work are indeed higher that those represented by this study.

The second perspective concerning PWU positions the behaviour in terms of resistance rather than organisational deviance. The education sector is often seen as a site of managerialism (Gleeson and Knights, 2008; Mather and Worrall, 2007) that has eroded teacher autonomy and deprofessionalised the workforce (Avis and Bathmaker, 2004; Mather, Worrall and Seifert, 2009) via the implementation of strategies of surveillance and punitive performance management. The result is work intensification (Mather, Worrall and Seifert, 2008) which leads to the boundaries between work and home life becoming ever more permeable as was evidenced in this study with the majority of respondents doing work at home, $40.07 \%$ extensively or very extensively - with increasing levels of work to do, teachers are subject to 'home invasion' (Page, 2011b), completing tasks at home in an effort to meet their responsibilities. From a labour process theory perspective, this is an example of time being 'appropriated' from employees via work intensification and longer hours; in response, workers will 're-appropriate' time (Paulson, 2011), engaging in personal activities at work. Through a lens of resistance, PWU at work for teachers can potentially be seen in these terms. With the work/life boundary permeable (Eddy et al., 2010) for teachers, it is perhaps unsurprising that with work intruding upon personal lives, personal lives would reciprocate with 'functional' PWU reported as common, as was found by Lim and Teo in their privatesector based study (2005). From a labour process theory perspective, such PWU can be seen as resistance rather than coping, as re-appropriating time from their employers. If teachers are answering emails at home, they may send personal emails at work; marking assignments outside of work may lead to personal banking at work; unpaid overtime to complete administrative tasks may encourage teachers to shop online while at work.

Yet labour process theory is not the only lens through which to view organisational resistance, we may also see it as micro-politics that emphasises the subjectivity of workers as they seek 'spaces of agency and minor degrees of freedom' (Spicer and Bohm, 2007, p1670). Drawing heavily on Foucault (e.g. Anderson, 2008; Covaleski et al., 1998; Thomas and Davies, 2005), the micro-political view of resistance focuses on the 'disciplinary mechanisms, techniques of surveillance and power-knowledge strategies' (Knights and Wilmott,2000, p423, citing previously published work by Knights and Wilmott) that seek to colonise the professional autonomy of workers. Within this context, routine resistance is the search for space, a distancing of the individual from corporatism that can be expressed in strategies such as cynicism (Stanley et al., 2005; Fleming, 2005), humour (Taylor and Bain, 2003; Fleming and Sewell, 2002) and impression management (Collinson, 2003). Here, then, PWU is perhaps the newest form of micro-political routine resistance, a search for agentive space in cyberspace. Distancing the self via PWU at work can also be seen as a means of impression management: those engaged in PWU may look as though they are working unless the screen is observable; even in open offices there are means to avoid detection (see Hope, 2007) by minimising the browser window when a manager is near or hiding one window behind a work-authorised one - Facebook can be hidden behind an electronic lesson plan, for example. From this perspective, PWU may appear identical to organisational citizenship behaviour (Bolino, 1999) for those whose screens are unobservable, and therefore evades detection.

Resistance, therefore provides one half of the workplace conflict that PWU foregrounds; the third perspective highlights the other side which positions PWU as potentially beneficial. While a minority of respondents spend excessive amounts of time on leisure browsing, for 
the vast majority, PWU may be a method of coping with the demands of their role and work intensification (Henle and Blanchard, 2008; Ugrin et al., 2007). Here, the internet is a means of providing an escape from work, a key means of coping within the educational workplace. While performing 'functional' PWU such as shopping or arranging insurance may be interpreted as resistance, as re-appropriation of time, searching for jobs or holidays online provides cognitive escape and a means of coping with the present demands of the workplace. Yet PWU may not just provide a means of coping with work intensification; it may also be a means of coping with 'workplace anomia' (Zoghbi-Manrique de Lara, 2007), alienation experienced at work as a result of increasing individualisation in the education workplace that has eroded solidarity (Ball, 2003). This issue is further exacerbated by the extent to which the teachers in this study worked at home. As such, 'social' PWU at work such as sending personal emails and social networking may be seen as resisting the anomia inherent in the contemporary workplace, a means of re-establishing personal connections. Here, then, is an area that requires further investigation, particularly the extent to which PWU at work was with other teachers within the same organisation. But more than being an escape-avoidance coping strategy, the findings suggest that PWU in moderation may actively be used to increase productivity supporting the argument of Coker (2011) and Oravec (2002). From this perspective, far from being problematic, PWU can be seen as an essential element of the modern teacher's hardiness (Kobasa, 1979), a means to reinstate control over work for the benefit of their own wellbeing and their effectiveness as a teacher. However, it must again be emphasised that, as the finding of increased productivity was self-reported, it must be treated with caution.

There is a final perspective concerning the potential benefit of PWU at work, one that concerns teachers' development, especially in terms of 'digital literacy' (Lankshear and Knobel, 2008) defined by JISC (Joint Information Systems Committee) as 'those capabilities which fit an individual for living, learning and working in a digital society' (Payton, 2012, p1). What is significant is that this definition blurs the boundaries between life inside and outside of work and suggests that the home/work boundary is permeable not just in terms of task engagement but also in terms of technology. As such, becoming digitally literate can be via social activities as much as work-based activities. Facebook and Twitter, for example, while originally intended as a means of social networking, are now being integrated into mainstream educational practices (Yang et al., 2011; Mahoney, 2012). Those best placed to exploit the educational opportunities offered by these online technologies are arguably those who have become familiar with them through social use. Conversely, teachers who have never used social networking in their private lives may be as resistant to incorporating these technologies into their practice as much as other e-learning strategies (e.g. Assude, Buteau and Forgasz, 2010; Huang et al., 2011). Straub (2009) supports this view and argues that much of the resistance of employees to the adoption of new technology occurs when it is mandated by the organisation. When the adoption of technology is voluntary and informal, initiated in personal lives, it is argued that its use within organisational activities becomes less problematic. Here, then, PWU at work may be seen as a means of increasing the digital literacies of teachers - as Lankshear and Knobel (2008, p9) argue, once practitioners have learnt and mastered technologies, they can then more easily translated into 'effective approaches for pursuing bona fide educational ends'. This may also be the case with teachers' PWU on their mobile phones - personal technology use that so seamlessly transcends the work/private life balance may even more greatly prepare teachers for exploiting mobile technology in their teaching practice, especially when mobile phones are so integral to the lives of the young people they teach. The extent to which this transfer from 
social mastery to implementation in teaching and learning occurs is an area of further investigation.

The question thus arises: what should senior managers do about PWU? On the one hand they could adopt a zero-tolerance approach with periodic monitoring which Henle et al (2009) suggests is effective. If PWU is a means of increasing productivity and coping with workplace stressors as this study suggests, tighter regulation of access to the internet could result in a less productive workforce. If PWU can develop the learning of teachers in terms of digital literacies, restricted access could be detrimental to the government's drive to further embed technology within teaching and learning. Evidence from the private sector suggests that companies are beginning to relax the prohibition of PWU at work with the number of companies blocking access to social networking dropping from its 2010 levels (Gaudin, 2012); this, it is argued, is transactional: as employees work longer hours, they are 'rewarded' with access to social networking at work. This strategy provides a means for mediating the conflict between work intensification and PWU as beneficial to the organisation. As such, the potential for PWU at work to act as a means of teacher development should not be underestimated. All education providers are engaged in attempts to increase the digital literacy of their staff to embed e-learning with the curriculum and pedagogy of their organisations. Yet, if mandated ICT training is met with staff resistance as Straub (2009) and others argue, then relaxing access to the internet may indeed prove to be the most effective means of developing the digital literacy of teachers.

\section{Conclusion}

With the internet becoming ever more ubiquitous in the work of teachers and trainers, its potential use for non-work purposes also grows as this study has shown. However, the findings also suggest that excessive PWU is confined to a minority of teachers in the sector with the majority engaging agentively and responsibly as a means of balancing their work and home life, coping with the stress of the sector and even as a means of resistance. The study also highlights the increasing use of mobile phones to engage in PWU, a means of evading official control of internet access via ' $3 G$ ' or non-networked browsing which organisations cannot prevent. Perhaps most importantly, the findings suggest a potential link between the development of digital literacy and PWU which has implications not just for teachers but for all organisations that require digital skills. The findings raise a number of areas for future research but also carry implications for senior managers in the sector who must balance the need for network security and teacher 'productivity' with the access needs of e-learning and the wellbeing of their staff.

\section{References}

Ackroyd, S. and Thompson, P. 1999. Organizational Misbehaviour. London: Sage Anandarajan, M. and Simmers, C. 2003. Personal Web Usage in the Workplace: A Guide to Effective Human Resources Management. Hershey, PA: Information Science Publishing

Anderson, G. 2008. Mapping academic resistance in the managerial university. Organization, 15 (2), 251-270

Assude, T., Buteau, C. and Forgasz, H. 2010. Factors influencing implementation of technology-rich mathematics curriculum and practices. Mathematics Education and Technology-Rethinking the Terrain, New ICMI Study Series, 13 (4), 405-419

Avis, J. and Bathmaker, A.M. 2004. The politics of care: Emotional labour and trainee 
further education lecturers. Journal of Vocational Education and Training 56 (1), 520

Ball, S. 2003. The teacher's soul and the terrors of performativity. Journal of Education Policy 18(2), 215-228

BBC News. 2012. Facebook drinking posts teacher Elizabeth Scarlett reprimanded. BBC News. Available from http://www.bbc.co.uk/news/uk-wales-south-east-wales16929442 [Accessed 15/01/2012]

Belanger, F. and Van Slyke, C. 2002. Abuse or learning? Communications of the ACM 45 (1), 64-65

Blanchard, A. and Henle, C. 2008. Correlates of different forms of cyberloafing: The role of norms and external locus of control. Computers in Human Behavior 24 (3), 10671084

Blau, G., Yang, Y., and Ward-Cook, K. 2006. Testing a measure of Cyberloafing. Journal of Allied Health 35 (1), 9-17

Bolino, M. C. 1999. Citizenship and impression management: Good soldiers or good actors? Academy of Management Review 24 (1), 82-98

Burawoy, M. 1979. Manufacturing Consent: Changes in the Labor Process Under Monopoly Capitalism. Chicago: University of Chicago Press

Carver, C. S. and Scheier, M. F. 1989. Assessing coping strategies: A theoretically based Approach. Journal of Personality and Social Psychology 56 (2), 267-283

Case, C. J., and Young, K. S. 2002. Employee internet management: Current business practices and outcomes. Cyberpsychology \& Behavior 5 (4), 355-361.

Collinson, D. 2003. Identities and insecurities: Selves at work. Organization 10 (3), 527-547

Court, S. and Kinman, G. 2008. Tackling stress in further education. London: University and College Union

Covaleski, M. A., Dirsmith, M. W., Heian, J. B. and Samuel, S. 1998. The calculated and the avowed: Techniques of discipline and struggles over identity in big six public accounting firms, Administrative Science Quarterly 43 (2), 293-327

Davis, R. A., Flett, G. L., and Besser, A. 2002. Validation of a new scale for measuring problematic Internet use: Implications for preemployment screening. Cyberpsychology and Behavior, 5, 331-345

de Lara, P. Z. M. 2011. Reconsidering the boundaries of the cyberloafing activity: The case of a university, Behaviour \& Information Technology 1, 1-11, iFirst article

de Lara, P. Z. M. 2007. Relationship between organizational justice and cyberloafing in the workplace: Has 'anomia' a say in the matter? CyberPsychology \& Behavior 10, 464470

Deci, E.L. and Ryan. R. M. 2004. Handbook of Self-Determination Research. Rochester, NY: University of Rochester Press

Eddy, E., D'Abate, C. and Thurston Jr, P. 2010. Explaining engagement in personal activities on company time, Personnel Review 39 (5), 639 - 654

Fleming, P. 2005. Workers' playtime? Boundaries and cynicism in a 'culture of fun' Program, The Journal of Applied Behavioral Science 41 (3), 285-303.

Fleming, P. and Sewell, G. 2002. Looking for the good soldier, Svejk: Alternative modalities of resistance in the contemporary workplace, Sociology 36 (4), 857-873

Folkman, S., Lazarus, R. S., Dunkel-Schetter, C., DeLongis, A. and Gruen, R. J. 1986. Dynamics of a stressful encounter: Cognitive appraisal, coping and encounter outcomes. Journal of Personality and Social Psychology 50 (5), 992-1003

Frydenberg, E and Lewis, R. 2002. Do managers cope productively? A comparison between 
Australian middle level managers and adults in the general community, Journal of Managerial Psychology 17 (8), 640-664

Garrett, R. and Danziger, J. 2008 On cyberslacking: workplace status and personal internet use at work. Cyberpsychology and Behavior 11 (3), 287-292

Gaudin, S. 2012. More companies are OK with employees using Facebook at work. Computerworld.

http://www.computerworld.com/s/article/9225558/More_companies_are_OK_with_e mployees_using_Facebook_at_work [Accessed 17/01/13]

Gleeson, D. and Knights, D. 2008. Reluctant leaders: An analysis of middle managers' perceptions of leadership in Further Education in England. Leadership 4 (1), $49-72$

Henle, C. and Blanchard, A. 2008. The interaction of work stressors and organizational sanctions on cyberloafing. Journal of Managerial Issues 20 (3), 383-400

Henle, C. A., Kohut, G., \& Booth, R. 2009. Designing electronic use policies to enhance employee perceptions of fairness and to reduce cyberloafing: An empirical test of justice theory. Computers in Human Behavior, 25, 902-910.

Hope. A. 2007. Panopticism, play and the resistance of surveillance: Case studies of the observation of student Internet use in UK schools. British Journal of Sociology of Education 26 (3), 359-373

Huang, R-T, Deggs, D., Jabor, M, Machtmes, K. 2011. Faculty online technology adoption: The role of management support and organizational climate. Online Journal of Distance Learning Administration 14 (2), 1-11

Kidwell, R. 2010. Loafing in the 21st century: Enhanced opportunities - and remedies - for withholding job effort in the new workplace. Business Horizons 53 (6), 543-552

Kim, S. and Byrne, S. 2011. Conceptualizing personal web usage in work contexts: A preliminary framework. Computers in Human Behavior 27 (6), 2271-2283

King, M. and Bruner, G. 2000. Social desirability bias: A neglected aspect of validity testing. Psychology and Marketing 17 (2), 79-193

Kobasa, S. 1979. Stressful life events, personality and health: An inquiry into hardiness. Journal of Personality and Social Psychology 37 (1), 1-11

Knights, D. and McCabe, D. 2000. Ain't misbehavin? Opportunities for resistance under new forms of 'quality' management. Sociology 34 (3), 421-436

Lankshear, C. and Knobel, M. 2008. Digital Literacies: Concepts, Policies and Practices. New York: Peter Lang

Lazarus, R. S., \& Folkman, S. 1984. Stress, appraisal, and coping. New York: Springer.

Lee, Y., Lee, Z. and Kim, Y. 2007. Understanding personal web usage in organizations. Journal of Organizational Computing and Electronic Commerce 17 (1), 75-99

Liberman, B., Seidman, G. McKenna, K. and Buffardi, L. 2011. Employee job attitudes and organizational characteristics as predictors of cyberloafing. Computers in Human Behavior 27 (6), 2192-2199

Lim, V. and Chen, D. 2012. Cyberloafing at the workplace: Gain or drain on work? Behaviour \& Information Technology 31 (4), 343-353

Lim, V. and Teo, T. 2005. Prevalence, perceived seriousness, justification and regulation of cyberloafing in Singapore: An exploratory study. Information \& Management 42, $1081-1093$

Lim, V., Teo, T. and Leng Loo, G. 2002. How do I loaf here? Let me count the ways. Communications of the ACM 45 (1), 66-70

Mahoney, D. 2012. Twitter for Teachers - Twitter for Teaching? E-Learning Island. http://donalomahony.edublogs.org/2012/03/20/twitter-for-teacherstwitter-for-teaching [Accessed 12/01/13]

Mather, K. and Worrall, L. 2007. Reforming further education: The changing labour process 
for college lecturers. Personnel Review 36 (1), 109-127

Mather, K., Worrall, L. and Seifert, R. 2009. The changing locus of workplace control in the English further education sector. Employee Relations 31 (2), 139 - 157

McBride, J., Milligan, J. and Nichols, J. 2006. Who's teaching the kids? Cyberslacking in the classroom. Journal of College \& Character 7 (1), 1-6

Noon, M. and Blyton, P. 1997. The Realities of Work. Basingstoke, Macmillan

Oravec, J.A. 2002. Constructive approaches to Internet recreation in the workplace. Communications of the ACM 45 (1), 60-63.

Page, D. 2011a. From principled dissent to cognitive escape: Managerial resistance in the English Further Education sector. Journal of Vocational Education and Training 63 (1), 1-13

Page, D. 2011b. Fundamentalists, priests, martyrs and converts: A typology of first tier management in Further Education. Research in Post-compulsory Education 16 (1), 101-121

Page, D. 2012. Teacher misbehaviour: An analysis of disciplinary orders by the General Teaching Council for England. British Educational Research Journal. ISSN 01411926 (Print), 1469-3518 (Online) (In Press)

Paulson, R. 2011. Layers of dissent: the meaning of time appropriation. Outlines - Critical Practice Studies 13 (1), 53-81

Payton, S. 2012. Developing Digital Literacies. http://www.jisc.ac.uk/media/documents/publications/briefingpaper/2012/Developing Digital_Literacies.pdf [Accessed 24/01/13]

Pee L., Woon, I. and Kankanhalli A. 2008. Explaining non-work-related computing in the workplace: A comparison of alternative models, Information \& Management 45 (2), 120-130

Prasad A. and Prasad, P. 1998. Everyday struggles at the workplace: The nature and implications of routine resistance in contemporary organizations. Research in the Sociology of Organizations 15, 225-257

Razavi, T. 2001. Self-report measures: an overview of concerns and limitations of questionnaire use in occupational stress research. Southampton, UK, University of Southampton, 23pp. (Discussion Papers in Accounting and Management Science, 01175)

Restubog, S., Garrcia, P., Toledano, L., Amarnani, R. Tolentino, L. and Tang, R. 2011. Yielding to (cyber)-temptation: Exploring the buffering role of self-control in the relationship between organizational justice and cyberloafing behavior in the workplace. Journal of Research in Personality 45 (2), 247-251

Reynolds, E. 2012. 'No wonder everyone is thick... inbreeding must damage brain development': Teacher insulted pupils on Facebook and sent chlamydia test kits to coworkers. MailOnline. http://www.dailymail.co.uk/news/article-2166520/TeacherNyanza-Roberts-insulted-pupils-Facebook-sent-colleagues-chlamydia-tests-hatecampaign.html [Accessed 24/12/12]

Robinson, S. L., and Bennett, R. J. 1995. A typology of deviant workplace behaviours: A multidimensional scaling study, Academy of Management Journal 38, 555-571.

Scott, J. 1985. Weapons of the Weak: Everyday forms of Peasant Resistance. New Haven, USA, Yale University Press

Selwyn, N. 2008. A safe haven for misbehaving? An investigation of online misbehavior among university students. Social Science Computer Review 26 (4), 446-465

Seymour, L. and Nadasen, K. 2007. Web access for IT staff: A developing world perspective on web abuse. The Electronic Library 25 (5), 543-557

Sheehan, K. (2001) E-mail survey response rates: A review. Journal of Computer-Mediated 
Communication 6 (2), 0-0

Skowronski, M. 2012. When the bored behave badly (or exceptionally), Personnel Review 41 (2), 143-159

Spicer, A. and Bohm, S. 2007. Moving management: Theorizing struggles against the hegemony of management. Organization Studies 28 (11), 1667-1698

Stanley, D. J., Meyer, J. P. and Topolnytsky, L. 2005. Employee cynicism and resistance to organizational change. Journal of Business and Psychology 19 (4), 429-459

Stratton, M. 2010. Uncovering a new guilty pleasure: A qualitative study of the emotions of personal web usage at work. Journal of Leadership \& Organizational Studies 17 (4), 392-410

Straub, E. 2009. Understanding technology adoption: Theory and future directions for informal learning. Review of Educational Research 79, 625-649.

Taylor, P. and Bain, P. 2003. 'Subterranean worksick blues': Humour as subversion in two call centres. Organization Studies 24 (9), 1487-1509

Thomas, R. and Davies, A. 2005. Theorizing the micro-politics of resistance: New Public Management and managerial identities in the UK public services. Organization Studies 26 (5), 683-706

Ugrin, J., Pearson, J. and Odom, M. 2007. Profiling cyber-slackers in the workplace: Demographic, cultural, and workplace factors. Journal of Internet Commerce 6 (3), 75-89

Vardi, Y. and Weitz, E. 2004. Misbehaviour in Organizations, New Jersey, Lawrence Erlbaum Associates

Vitak, J., Crouse, J. and LaRose, R. 2011. Personal internet use at work: Understanding cyberslacking, Computers in Human Behavior 27 (5), 1751-1759

Weatherbee, T. 2010. Counterproductive use of technology at work: Information and communications technologies and cyberdeviancy. Human Resource Management Review 20 (1), 35-44

Yang, Y., Wang, Q., Woo, H and Quek, C. 2011. Using Facebook for teaching and learning: A review of the literature. International Journal of Continuing Engineering Education and Life Long Learning 21 (1), 72-86 